Šafranj, J., Gojkov-Rajić, A., \& Bogdanović, V. (2021). The ideal L2 self as a Factor of self-motivation in willingness to communicate, International Journal of Cognitive Research in Science, Engineering and Education (IJCRSEE), 9(2), 189-202.

Original scientific paper

UDK:

159.953.072

81 '23

Received: May, 14.2021.

doi: 10.23947/2334-8496-2021-9-2-189-202

Revised: June, 19.2021

Accepted: July, 26.2021.

Check for updates

\title{
The Ideal L2 Self as a Factor of Self-Motivation in Willingness to Communicate
}

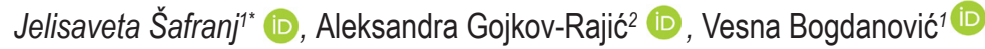 \\ 'Jelisaveta Šafranj, Faculty of Technical Sciences, University of Novi Sad, Serbia, e-mail: savetas@uns.ac.rs \\ ${ }^{2}$ Aleksandra Gojkov-Rajić, Faculty of Teacher Education, University of Belgrade, Serbia, e-mail: rajis@mts.rs \\ ${ }^{1}$ Vesna Bogdanović, Faculty of Technical Sciences, University of Novi Sad, Serbia, e-mail: vesna241@uns.ac.rs
}

\begin{abstract}
Theoretical basis of this paper is the heuristic L2 Motivational Self System (L2MSS). The research aims to determine the degree to which the ideal $L 2$ self can be regarded as a significant factor with regards to its power to make a difference in students' actual motivated behaviour in L2 communication. The research sample consists of 396 students. The ideal L2 self is a predictor variable. Willingness to communicate and the obtained grades are criterion variables. Gender, period of time spent learning English / German, and whether students are residing in the country where the target language is spoken are all moderator variables. Systematic non-experimental observation method based on Dörnyei and Taguchi's survey was used in this study. Cronbach's alpha indicated high reliability in the presented sample (.92). Willingness to communicate was investigated using McCroskey's questionnaire. The findings indicate a rather complex picture of the observed L2 MSS constructs and the importance of their components in the field of $L 2$ learning. Therefore, for further research, it is suggested that the ideal L2 self should be divided into two constructs: obligations that the individual would like to comply with and obligations that others expect him/her to comply with. The contribution of the L2 learning experience should also be considered because otherwise, it is difficult to determine the progress of the model design and what to do with it in practice.

Keywords: Ideal L2 self, self-motivation, willingness to communicate in L2 language.
\end{abstract}

\section{Introduction}

Over the last two decades, motivation has come to be regarded as one of the basic variables and an important factor in predicting the efficiency of learning. In the modern, globalised world and as a result of the growing need for learning foreign languages, motivation has become the focus of attention in the field of language studies. This is especially visible in the field of English language, which is considered to be lingua franca nowadays, but is equally important in learning other languages (Gojkov-Rajić et al., 2021a; Evtyugina et al., 2020). Given the fact that foreign languages are being learned from an early (preschool) age, and that their mastery is at the top of the list of currently required competencies in almost all educational policies in the world, it is understandable that, as the result of these changes, the role of motivational orientation in learning a second/foreign language (L2 - English, and others) is the main focus of language studies. Studies on motivation in learning a second/ foreign language (L2) have evolved in recent decades in line with changes in understanding constructs in personality psychology, and in the last two decades, this motivation has been linked to the concept of self (Dörnyei and Ushioda, 2011). Thus, the need to understand L2 motivation is also related to existing constructs in personality psychology. The term I, or self, has become the main theoretical construct that dominates the field of studying motivation in foreign language learning (Gojkov-Rajić, Šafranj and Gojkov, 2021b).

Researchers are focused on validating the L2 Motivational Self System (L2MSS) model (Dörnyei, 2006), which includes the ideal L2 concept in predicting willingness to communicate (WTC). Dörnyei (2006) presented the L2 motivational self-system (L2MSS) which, he believes, can explain individual differences in motivation when it comes to foreign language learning. Elements of several theoretical assumptions related with the concept of self (Markus and Nurius, 1986; Dörnyei, 2006; Higgins, 1987; Gardner et al., 2010, etc.) are interlaced within this model, thus attempting to understand individual differences in language learning motivation.

"Corresponding author: savetas@uns.ac.rs 
Šafranj, J., Gojkov-Rajić, A., \& Bogdanović, V. (2021). The ideal L2 self as a Factor of self-motivation in willingness to communicate, International Journal of Cognitive Research in Science, Engineering and Education (IJCRSEE), 9(2), 189-202.

The basic assumption of the L2MSS is that when individuals notice discrepancy between their current state and the future self-guide (i.e. ideal or necessary), this deviation can function as a motivator to bridge the perceived gap and achieve the desired goal or state. The first broader examination of this model was conducted by Dörnyei (2009a, 2009b), reporting on numerous empirical studies that confirm the values of the proposed L2MSS model. Consequently, the interest in the field of language motivation has seen tremendous growth. Over a single decade, hundreds of studies have appeared worldwide (Boo, Dörnyei and Ryan, 2015), making L2MSS the prevailing theoretical framework (Boo, Dörnyei and Ryan, 2015). As the literature states, this can be attributed to the model's versatility and ability to adapt a wide range of perspectives from different theoretical orientations to the field of motivation to learn a foreign language (Ibid.).

The L2MSS consists of three main components (Dörnyei, 2006, 2009a):

- The first component is the ideal L2, which refers to the desire and hope of an individual to master an ideal level of knowledge of the language he/she wants to reach, or which would be ideal or desirable to reach. Thus, the ideal L2 represents one's hopes and desires;

- The second component, the ought-to L2 self, is needs-oriented and indicates the need to know/master L2 of the country where an individual would like to settle. This need, and therefore the motivation stimulated by the expectations of others, represents the expectations that were projected and imposed by others.

- The L2 learning experience is at the second level and refers to one's experience in the immediate learning environment, including aspects such as: the teacher, the curriculum, and the peers.

For the purpose of understanding research findings presented in this paper better, it is important to highlight the relation of $L 2$ self construct with human behaviour patterns that allow interaction between motivational psychology and personality psychology. This has opened room for a new research area of possible self (Dörnyei, 2009b). According to Marcus and Nurius (1986), the notion of possible self aims to explain the way the individual currently perceives his/her potential, conceived as the self, by means of which he/she can determine the emergence of his/her predicted behaviour in the future. According to the above-mentioned authors, the possible self (the ideal self) represents what an individual would do to realize his/her intentions or desires; what he/she wants to become, what he/she could become (Markus and Nurius, 1986). Thus, it has been concluded that L2MSS is based on the theory of possible selves ("L2 Motivational Self System") proposed by Dörnyei (2006, 2009b). As mentioned earlier, the same author recognizes three main components of this model: the ideal L2 - individual's desire and hope to adopt an ideal level of language proficiency, the ought-to L2 self - expectations projected and imposed by others, and the L2 self-experience - immediate learning environment. Another important conclusion is that the components of motivation in this framework not only point towards understanding motivation within oneself but also establish that it can be used to mobilize personal strength for $L 2$ achievements in foreign language learning, as it is directly related to the individual's current perception of himself/herself and ideally oriented towards the L2 future (Dörnyei and Chan, 2013; Williams, Mercer and Ryan, 2016). It could, therefore, be concluded that the essence of this understanding consists of the idea of progressing gradually from the current to a more desirable, higher state, which largely depends on the person's willingness to reach the visualised standards of his/her ideal self. If individuals increase their awareness with regard to acquiring new skills and strategies necessary to fill this gap, this self-awareness will actually represent motivation, i.e. an incentive to invest more effort in developing the intended behaviour. It could be pointed out here that the L2MSS motivational system aims to explain the way in which a person's current perception of his/her potential, conceived as an I/self, can affect the emergence of predicted behaviour in the future. Therefore, the possible self represents what an individual would like to become, what he/she could become (Markus and Nurius, 1986). Rooted in the theory of possible selves, the L2MSS proposed by Dörnyei $(2006,2009 b)$ as a new framework, not only locates motivation within the self but also assumes that directing efforts towards L2 learning achievement is immediately associated with one's current view of himself/herself and ideally oriented towards the L2 future (Dörnyei and Chan, 2013; Williams, Mercer and Ryan, 2016). Consequently, the essence of L2MSS is in the idea that the ideal self operates as a driver for progressing gradually from the current to a more desirable state. The higher state mainly depends on one's willingness to reach the visualised standards of the personal ideal self.

Accordingly, previously mentioned potential of possible selves acts as a motive for future actions, which suggests that the ideal $L 2$, representing "characteristics that one would ideally want to possess" (Dörnyei, 2014), can increase the willingness to communicate (WTC).

Willingness to communicate is another, also frequently studied variable in foreign language learning and teaching research. In general, it is based on the belief that one participates in communication of one's own free will, and WTC as a construct assumes that avoiding spoken discourse is likely to result in 
Šafranj, J., Gojkov-Rajić, A., \& Bogdanović, V. (2021). The ideal L2 self as a Factor of self-motivation in willingness to communicate, International Journal of Cognitive Research in Science, Engineering and Education (IJCRSEE), 9(2), 189-202.

distorted learning effects in L2 contexts (Öz, 2016). WTC is essentially an abbreviation for "a composite variable of a multitude of individual variables, acting on the acquisition and use of a second language, resulting in a construct in which psychological and linguistic factors are integrated in an organic way" (Dörnyei, 2006, 2009a). Therefore, WTC represents the level of psychological willingness to direct and maintain L2 communication and is widely considered to be the primary factor behind the success in L2 learning (Maclntyre and Doucette, 2010).

Processes behind the development of the L2 WTC and its essential characteristic related to the inter-group variables and processes woven into a set of characteristics that are supposed to affect $L 2$ learning and communication are clearly shown in Figure 1 (Maclntyre et al., 1998).

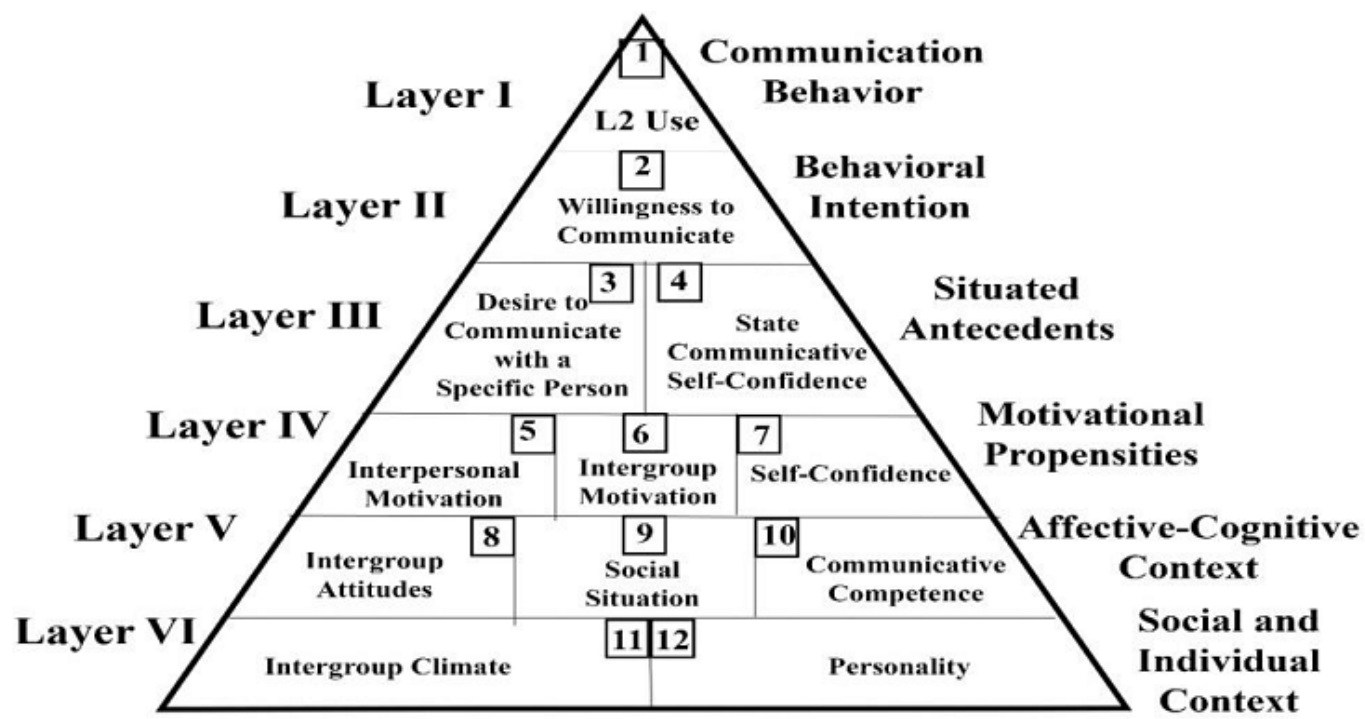

Figure 1. Heuristic model of L2 WTC (Maclntyre et al., 1998)

This chart presents the proposed heuristic WTC model in the form of a pyramid, which provides a multidimensional construct in a six-degree framework that encompasses the psychological and communication dimensions of the language, such as self-confidence, attitude, desires, willingness to communicate, etc. (Maclntyre et al., 1998). Those are believed to affect L2WTC.

Figure 1 (Maclntyre et al., 1998) shows the relation between the constructions of the self and the behavioural patterns within the field of motivational psychology and personality psychology in the newly created language research field that relates to the possible self (Dörnyei, 2009b), for which Marcus and Nurius (1986) seek to explain how the individual's current perception of his/her potential, conceived as I can determine the emergence of predicted behaviour in future. As previously concluded, the possible I represents what an individual would do, what he/she would like to become, what he/she could become (Markus and Nurius, 1986). This points to the assumption that the L2MSS, proposed by Dörnyei (2006, $2009 \mathrm{~b}$ ), with the above-mentioned components of the ideal L2 self (recognizing the needs of the L2 self and L2 learning experience) is like a framework for initiating motivation in terms of positioning it within ourselves. But it also goes a step further, in terms of direction and guidance; therefore, it has the property of driving the effort towards L2 learning achievement. The chart with the heuristic L2 WTC model (Macintyre et al., 1998) presents the relation of the current self (self-view) and is ideally oriented towards the future L2, which has been the focus of much research for the last two decades (Dörnyei and Chan, 2013; Williams, Mercer and Ryan, 2016). This model is a graphical representation of the previously developed idea of progressing gradually from current to a more desirable state with a significant motivating role towards achieving a higher position, which mainly depends on the person's willingness to reach the visualised standards of the ideal self. Consequently, higher level of awareness, as a perceived need to acquire new skills and strategies necessary to fill this gap, i.e. self-awareness, turns into motivation, becoming an instrument that encourages investment of more effort in developing predicted behaviours. Accordingly, the above-mentioned authors explain the potential of possible selves to act as a stimulus for future activities in mastering a foreign language, i.e. communication, where ideal L2 is a part of the self "characteristics that someone would ideally want to have" (Dörnyei, 2014: 65), which can further increase willingness to communicate (WTC). This prompts researchers to focus on the explained construct, as it combines (see Figure 1) many variables of the individual that have been identified as the ones affecting the acquisition and use of a second language, i.e. psychological and linguistic factors, which are integrated organically 
Šafranj, J., Gojkov-Rajić, A., \& Bogdanović, V. (2021). The ideal L2 self as a Factor of self-motivation in willingness to communicate, International Journal of Cognitive Research in Science, Engineering and Education (IJCRSEE), 9(2), 189-202.

(Dörnyei, 2006). Thus, it can be seen that WTC is actually intertwined psychological willingness for initiating and maintaining L2 communication, and therefore, at the level of current knowledge of these constructs, it is widely accepted as the primary success factor in L2 learning (Maclntyre and Doucette, 2010). At the same time, WTC is the initiator of many studies seeking to validate it. The findings of some of these studies are presented in this paper.

After a preliminary consideration of theoretical assumptions, the starting point of this research has been the assumption that the presented heuristic L2 WTC model is comprehensive and that it clearly explains the processes underlying the development of L2 WTC, relying on intergroup variables, which are the basis of processes rooted in individual characteristics that are assumed to affect L2 learning and communication. Another starting point is the assumption that this theoretical model encompasses proximodistal ambiguous construct that integrates linguistic, psychological, and communicative dimensions of a language. These dimensions are expected to affect L2 WTC (Maclntyre et al., 1998). Another important point of research, the findings of which have been presented in this paper, is the conclusion that the first three layers of the six-layer pyramid model represent situation-specific influence, while the other three layers at the bottom refer to the individual's stable characteristics (Ibid.). The first two layers, behavioural intention and communication behaviour, build the upper part of the pyramid and are considered location-sensitive parameters that show variances among individuals at a certain time and in a certain place when communicating. On the other hand, when observed from the top to the bottom, the chart moves to more visible specific influences related to long-term characteristics. In terms of content, these layers relate to the following:

- Layer VI contains most of the most distant elements, intergroup climate, and personality; these are considered stable and include innate hereditary characteristics.

- Layer $\mathrm{V}$ reflects the affective-cognitive state of the individual and mainly explains personal attitudes and motives.

- Layer IV, similar to the previous layer, brings together communication-oriented tendencies that exert a very consistent influence in different situations (Maclntyre et al., 1998).

By means of analysing the model presented above, it can be concluded that the layers and sections presented are interdependent: each subsequent layer rests on the previous one, and as long as these relations are permanent and the time parameters given in the diagram work efficiently in the desired direction, the person will be progressing gradually towards reaching his/her goal, which is at the top of the pyramid and relates to L2 communication. Most researchers conclude that this model ignores the shortcomings of previous models that had limited potential effects on L2 WTC, because they treated this construct mainly as a personality trait, thus lacking a wider range of constructs that constitute potential predictors of communication, i.e. L2 WTC (Peng, 2012).

As for the topic of this paper, it is important to mention that, in recent decades, studies have been increasingly focusing on potential L2 WTC predictors, such as extraversion/introversion, self-confidence, anxiety, integrativeness, i.e. personality traits, but also motivation itself (Yashima, 2002). Special interest has been shown in individual's communicative competencies, as one of the correlates in WTC (Kim, 2004; Peng and Woodrow, 2010). Therefore, researchers conclude that there is potential parallelism between one's ideal L2 and L2 WTC. Research findings show that the ideal L2 self constitutes larger part of planning efforts that facilitate development of L2 communication skills (Noels, 2009).

Having in mind all these considerations, this study aims to provide further insights into a potential correlation that seems to exist between the above-mentioned ideal L2 and willingness to communicate among students at Serbian universities. When it comes to WTC, the situation is complex and not completely clarified but the interest in this topic is stimulated by the fact that a large number of studies is focusing on the relationship between L2 WTC and several variables, such as perception of competence and anxiety (Baker and Maclntyre, 2003), motivation (Peng, 2007), identity styles (Zarrinabadi, 2014), age, gender (Donovan and Maclntyre, 2004) and attitude (Yashima, 2002). Special focus is placed on the notion of "perceived communicative competence" (Baker and Maclntyre, 2003). Moreover, studies dealing with L2 WTC predictors (Peng and Woodrow, 2010; Yashima, 2002; Yashima, Zenuk-Nishide and Shimizuet, 2004; Yu, 2008) are emerging with arguments about the individual's perceived communication abilities that can be considered a strong L2 WTC predictor (Mehmet, 2020; Shirvan et al., 2019). Namely, there are several studies dealing with the predictive value of the ideal L2 self in WTC in L2 context (Peng, 2015). Their findings show that there is interrelationship among variables such as the L2 motivational selfsystem, L2 anxiety, and L2 WTC. Peng (2015) failed to find any significant correlation between the ideal L2 and L2 WTC, whereas Munezane (2013) noted a direct path from the ideal L2 to the L2 WTC. His findings supporting the statement that the ideal L2 only predictively foresees L2 WTC have been confirmed by a subsequent study (Munezane, 2015). Similarly, Kanat-Mutluoglu (2016) illustrates the predetermined path 
Šafranj, J., Gojkov-Rajić, A., \& Bogdanović, V. (2021). The ideal L2 self as a Factor of self-motivation in willingness to communicate, International Journal of Cognitive Research in Science, Engineering and Education (IJCRSEE), 9(2), 189-202.

from the ideal L2 to L2 WTC. Research findings on motivation in second and foreign language learning are also interesting for the topic of this paper. Dörnyei (2006) argues that studies on L2 motivation should adopt a two-stage approach, one for learning English and one for learning some other foreign language. Therefore, he proposed a new L2 motivation as a framework that takes into account the role of English as a world language. A study conducted in Croatia (Martinović, 2018) examined the motivation to learn English or German among Croatian students using this new framework (L2MSS), taking into account different motives for learning English or German as a foreign language. The results indicated that the period of time spent learning English / German language insignificantly affected students' motivational disposition. Higher levels of motivation regarding $L 2$ and stronger ideal $L 2$ self were found among students as pragmatic motives, associated with career success and higher grades. Some difference was also found among students of biotechnology, who showed the lowest level of L2 motivation. Some difference regarding gender was found across different kinds of motivations, including higher levels of intended effort and pragmatic motives related to avoiding negative outcomes among female respondents, while male respondents reached higher levels on the ideal L2 self-assessment scale.

It is crucially important for the topic of this paper, and the research itself, to include findings of meta-analysis on the L2 self-motivational system in the initial considerations (Dörnyei, 2006, 2009a). In meta-analysis, based on 32 reports, which included 39 unique samples and almost 33,000 respondents learning foreign languages, three components of the L2 motivational system i.e. ideal L2 self, ought-to L2 self, and L2 learning experiences, were significant predictors of subjective effort, although weaker predictors were also found in objective measures of achievement. In addition, significant heterogeneity was observed in most of these correlations.

As previously mentioned, the ideal $\mathrm{L} 2$ self has received a lot of attention from researchers in the recent decades. However, as it was also stated, the results led to a series of conclusions, some of which were polarized. Those who inspired this research will be listed. Accordingly, based on the findings, the predictive validity of the ideal L2 self is described as "direct" (Dörnyei and Ushioda, 2011) and "solid confirmation" (Dörnyei, 2009b) with granted validity (Dörnyei, 2014). Moreover, Dörnyei and Ryan (2015) claim that all validation studies conclude that the L2 motivational self-system corresponds well with the data. Ghanizadeh and Rostami (2015) further state that their results verify the model in virtually every context. These comments generally refer to the ideal $L 2$ self, which is also confirmed in the findings of other researchers (Ghanizadeh, Eishabadi and Rostamil, 2016; Henry, Davydenko and Dörnyei, 2015; Islam, Lamb and Chambers, 2013; Teimouri, 2017).

However, there are also findings of other researchers who express considerable reluctance (AlHoorie, 2018). The research conducted by Kim and Kim (2011) shows that in the case of Korean high school students ideal L2 self is not a predictor of school grades. Therefore, they conclude that motivation based on the development of the ideal L2 self through dominant visual aptitude is irrelevant to the level of academic achievement. Similarly, Lamb (2012) applied the C-test to students in Indonesia and also found that the ideal L2 self cannot predict their knowledge (Al-Hoorie, 2018). He also noted that, although his students would like to see themselves as future users of the English language (ideal L2 self), what made them more likely to invest effort in learning was their assessment of whether they felt positive in the learning process (Ibid.). In Canadian context, Maclntyre and Serroul (2015) examined the relationship between the ideal L2 self and the actual L2 performance in their idiodynamic paradigm, which measures individual motivational variability over time. As they reported, they failed to find any evidence that the ideal L2 self was dynamic or adapted to the changing requirements of the task. In Iranian context, Papi and Abdollahzadeh (2012) also found that the ideal L2 self fails to predict actual classroom behaviour (Al-Hoorie, 2018).

As for previous findings, it could be noted that the students' ideal vision of their future L2 self fails to show much influence on their motivated behaviour in English classrooms (or some other foreign language), or vice versa. In other words, regardless of the level of the students' ideal L2 self, their actual motivated behaviour in the classroom will remain unchanged, and regardless of the student's motivation in the class, their ideal L2 will be unchanged (Papi and Abdollahzadeh, 2012: 588).

In Saudi context, Moskovsky et al. (2016) found the ideal L2 self to be a negative predictor of language proficiency. Researchers claim that the results generally "indicate, at best, a weak link between self-guidance and achievement".

Limited space does not allow more arguments in this direction, but they can be found in literature, and based on everything stated above, it could be concluded that new findings indicate a rather complex scenario of the observed constructs and their importance in foreign language learning. It is probably due to the applicability of the model to different contexts or participants, or the use of different outcome measures (Al-Hoorie, 2018). In his meta-analysis, Al-Hoorie (2018) offers a good description of the situation, noting 
Šafranj, J., Gojkov-Rajić, A., \& Bogdanović, V. (2021). The ideal L2 self as a Factor of self-motivation in willingness to communicate, International Journal of Cognitive Research in Science, Engineering and Education (IJCRSEE), 9(2), 189-202.

that researchers agree that the ideal L2 self should be improved. Dörnyei and Chan (2013) admit that although (according to Al-Hoorie) the ideal L2 self plays certain role in shaping students' motivational thinking, in many linguistic contexts it lacks the power to make a difference in their actual motivated behaviour. It is also noted that, while participants considered external pressure valid and intended to adjust their behaviour accordingly, this intended effort failed to reflect in their actual grades.

Research results further conclude that it is necessary to include the difference between oughtto $L 2$ self/others, both in the ideal L2 and what L2 should be. From this perspective, the ideal L2 self should be divided into two constructions: one representing one's hopes and one representing the hopes of others. Similarly, self-governing L2 should be divided into obligations that one would like to perform and obligations that others expect to be performed (Papi and Teimouri, 2012). In one of the few quantitative studies, Teimouri (2017) tested the significance of ought-to L2 self/others for the language learning context in which one of the significant results found supports the difference between ought-to L2 self/others, but not the ideal L2 self. Teimouri argues that ideals are highly internalized and consequently they may not be divided into those that relate to the self and the ideals of others (what is needed). However, the possibility to assess the contribution of these findings in terms of improving the original construction is related to the reference framework. Thus, without quantifying the predictive validity of the original $L 2$, and the other one (which is needed), it is considered difficult to determine the progress of this construction. Therefore, findings of new tests in new meta-analyses are expected, which is, actually, the purpose of this research.

The available space limits broader analyses of findings related with available meta-analyses, but it would be important to mention the findings that open up questions regarding the construct marked as "L2 learning experience" or "attitudes towards language learning". Meta-analysis conducted by You, Dörnyei, and Csizér (2016) noted the existence of significant overlap in the scale used to measure them, as well as the fact that the L2 learning experience functions at a different level than the ideal L2 self or other expectations regarding the L2 self. On the contrary, the L2 learning experience deals with attitudes and assessments related with the current learning environment and does not act as a future-oriented self-guide. It is believed that this construct has received very little attention due to the growing interest in self-guidance over the recent years (Boo, Dörnyei and Ryan, 2015). Dörnyei describes the L2 learning experience as a situated, executive motive (Dörnyei, 2009b) and model's causal dimension (Dörnyei, 2006). Findings of meta-analyses indicate that little has been done to clarify the role of such executive motives and mechanisms behind their causal action, making it the least theorized construct in L2MSS (Ushioda, 2011). Nevertheless, the L2 learning experience has been described as the strongest predictor in L2MSS (Lamb, 2012; Teimouri, 2017). It has also been concluded that most studies that tested this construct in the field of foreign languages are observational and that the standard design includes administering a scale for students and examining the relationship (correlation, regression, or modelling of structural equations) between the results on this scale and other criteria measured. Marks, Fairris and Belecheand (2012) emphasize the need for caution in interpreting observational studies, citing several factors that may lead to distortion of findings, which raises serious doubts as to the validity of these studies. In addition, the analyses of experimental research in several educational studies conducted in different parts of the world (Al-Hoorie, 2018) are also being questioned. This is just another stimulus for the question behind this research, aimed to contribute to the accumulation of sufficient findings related with quantitative studies. Assessment of the confidence interval of effects reported in these studies would contribute to the clarification of conflicting results.

Thus, in line with the title, the subject of this research is the ideal L2 self, with close attention focused on its importance regarding self-motivation in willingness to communicate in a foreign language. Therefore, the question that guides this research is: what is the role of the ideal L2 self in shaping students' motivational way of thinking when it comes to their willingness to communicate in a foreign language, or what is the role of the ideal L2 self in shaping motivation to communicate in a foreign language? In other words, to what degree can the ideal L2 self be considered a significant factor in observing the power of making a difference in students' actual motivated behaviour in situations of foreign language communication?

The intention is to examine the importance of the ideal L2 self as a factor in self-motivational willingness to communicate. This would contribute to a safer qualification of the predictive validity of the ideal L2 self when it comes to communicating in a foreign language, taking into consideration needsoriented $L 2$ and $L 2$ self-experience, as well as to a more reliable assessment of the importance of designing motivational models, providing thereby a clearer orientation in directing motivation towards foreign language communication.

The basic assumption refers to the following: the ideal L2 self is a significant factor of selfmotivational willingness to communicate in a foreign language. 
Šafranj, J., Gojkov-Rajić, A., \& Bogdanović, V. (2021). The ideal L2 self as a Factor of self-motivation in willingness to communicate, International Journal of Cognitive Research in Science, Engineering and Education (IJCRSEE), 9(2), 189-202.

Working hypotheses:

- The examined students have a good motivational precondition in terms of directing their efforts towards progressing gradually from the current to a more desirable state. Their willingness to reach visualised standards of the personal ideal self is high, i.e. they have a high ideal L2 self within the L2MSS motivational system.

- The ideal L2 self is in significant positive correlation with the willingness to communicate, which confirms its motivational potential for foreign language learning.

- The relationship between the ideal L2 and WTC (willingness to communicate) is influenced by the following moderator variables: gender, time spent in the country where the target language is spoken, and the period of time spent learning a foreign language.

\section{Materials and Methods}

The sample consisted of 396 participants from two faculties: 277 from the Faculty of Technical Sciences, University of Novi Sad, and 119 from the Faculty of Teacher Education, University of Belgrade. 168 were female participants (56.8\%), and the average age of the subjects was 20.54 years $(S D=1.77$ ). 59 students resided in the country where the target language was spoken, with the period of time they spent in these countries ranging between 2 weeks and 12 years.

Variables

- predictor variable: ideal L2 self;

- criterion variables: willingness to communicate, obtained grade in learning a foreign language;

- moderator variables: gender, the period of time spent learning English / German, and whether students resided in the country where the target language is spoken or not.

\section{Organization and instruments}

The research was conducted in the academic year 2019/2020, using the method of systematic non-experimental observation, based on survey procedure. The ideal $L 2$ self-assessment was carried out using a 10-item questionnaire (Dörnyei and Taguchi, 2009), intended for self-assessing the ideal level of knowledge of the language to which the respondent aspires. The reliability was checked using Cronbach's alpha, and in the examined sample, it was $=.92$.

Willingness to communicate was investigated using a questionnaire (WTC; McCroskey, 1992) that offered 20 hypothetical situations in which examinees may decide to communicate or not. Situations ranged from everyday situations, such as talking to your friend, to challenging situations, such as giving a speech on an official occasion. For each situation, participants were asked to respond choosing an option from 0 to 100, indicating the level of their willingness to communicate in a given situation. The reliability was checked using Cronbach's alpha, and in this sample, it was $=0.90$.

\section{Data analysis}

For the purpose of assessing the relationship between the ideal L2 self, the willingness to communicate, the obtained grade, the period of time spent learning English/German language, the gender, and whether participants resided in the country where the target language is spoken or not, the correlation coefficient was calculated: Pearson correlation coefficient for continuous and point-biserial correlation coefficient for binary variables (gender and whether the participant resided in the country where the target language is spoken) was calculated. In order to clarify the results in a more systematic way and in order to assess a partial predictive influence of predictors (ideal L2, grade obtained, the period of time spent learning English/ German, gender, and whether participants resided in the country where the target language is spoken), multiple regression analysis was performed on willingness to communicate.

Possible moderations between the ideal L2 self and other predictors were checked using the macro PROCESS for SPSS (Hayes, 2009). A total of 4 moderations was checked with 1) gender, 2) whether participants resided in the country where the target language is spoken, 3) grade obtained, and 4) the period of time spent learning English / German, as potential moderators between the ideal L2 self and willingness to communicate. 


\section{Results}

Descriptive statistics for research variables are presented in Table 1. Skewness and kurtosis values of all research variables were in the proposed range of \pm 1.5 (Tabachnick and Fidell, 2013), indicating that there were no significant deviations from univariate normal distributions.

Table 1.

Descriptive statistics of research variables

\begin{tabular}{ccccccc}
\hline Variable & Min & Max & Mean & SD & Sk & Ku \\
\hline Ideal L2 self & 13 & 50 & 39.50 & 9.04 & -0.80 & -0.19 \\
Duration of learning & 6 & 19 & 12.84 & 2.10 & -0.26 & 1.12 \\
Grade & 51 & 100 & 83.48 & 12.98 & -0.83 & -0.23 \\
WTC & 0 & 2000 & 1134.09 & 398.83 & -0.17 & -0.14 \\
\hline
\end{tabular}

From basic descriptive indicators for continuous research variables, it can be seen that the average value of WTC was 1134, whereas the standard deviation was $~ 400$. Given the normal distribution of this variable, it can be concluded that in our sample $\sim 68 \%$ of respondents have a self-assessment WTC score between 734 and 1534. For the ideal L2 self, the average score was 39.50 and the standard deviation was 9. Most scores were between 30 and 49, indicating that the L2 scores were quite high. The scores in the sample were quite high because the average score was 83.48 .

Analysing these results from the perspective of the ideal L2 within L2MSS motivational system, i.e. the understanding that the ideal L2 aims to explain how a person's current perception of his/her potential, conceived as I/self, can affect the emergence of predicted behaviour in the future, it can be concluded that the surveyed students have good motivational precondition for directing their efforts towards progressing gradually from the current to a more desirable state, as a result of their high willingness to reach visualised standards of the personal ideal self. Thus, it could be further expected that this self-awareness towards acquiring new skills and strategies in the field of foreign languages will turn into motivation and become an incentive to invest more effort in developing the intended behaviour. These results confirm the first working hypothesis.

\section{Correlation between the observed variables}

Correlation between research variables is presented in Table 2. The ideal L2 self is in insignificant positive correlation with the following variables: whether the participant resided in the country where the target language is spoken, the period of time spent studying a foreign language, the grade, and the willingness to communicate. These correlations were of low intensity.

Table 2.

Correlations between research variables

\begin{tabular}{|c|c|c|c|c|c|c|}
\hline & L2 self & Gender & Country & Study years & Grade & WTC \\
\hline $\begin{array}{l}\text { Ideal L2 } \\
\text { self }\end{array}$ & 1 & 0.05 & $.11^{*}$ & $.18^{* *}$ & $.38^{* *}$ & $.20^{\star \star}$ \\
\hline Gender & 0.05 & 1 & -0.02 & 0.00 & $-.19 * *$ & -0.02 \\
\hline Country & $.11^{*}$ & -0.026 & 1 & $.13^{*}$ & 0.05 & 0.09 \\
\hline $\begin{array}{l}\text { Duration } \\
\text { of learning }\end{array}$ & $.18^{* *}$ & 0.00 & $.13^{*}$ & 1 & 0.07 & -0.09 \\
\hline Grade & $.38^{* *}$ & $-.19^{* *}$ & 0.05 & 0.07 & 1 & 0.06 \\
\hline WTC & $.20^{\star *}$ & -0.02 & 0.09 & -0.09 & 0.06 & 1 \\
\hline
\end{tabular}

It has been observed that the ideal $\mathrm{L} 2$ self is related to whether participants resided in the country where the target language is spoken, the period of time spent learning English/ German, the obtained grade, and the willingness to communicate. For the most part, these correlations are very low, only the correlation between the L2 self and the obtained grade are of moderate intensity. Generally, those with a higher L2 self also have higher grades. These findings are noteworthy, as they highlight the variable 
assessment of success in foreign language proficiency as more significant than the others, indicating that there is a possibility that the status of the ideal L2 is not autonomous, although significant for willingness to communicate in a foreign language, compared to other components of the observed model (referring to the L2 expectations projected and imposed by others and L2 learning experiences in the immediate learning environment, including aspects such as the teacher, the curriculum and the peers). This means that further studies on this model should focus more on these two components. This is particularly important for L2 learning experience, as it is directly related to the motivational context in the classroom, i.e. the teaching, the curriculum, the context in which L2 learning and teaching take place.

The position of the grade variable is especially important, i.e. the grade obtained in learning a foreign language within the observed correlative composite of variables, because it suggests potential significance of the ideal L2 in achieving success, which justifies its role as a motivation driver. We say "potential significance", because the other components of the L2MSS, which is the basis of this paper, have not been specifically considered, and the above-mentioned studies see their contribution as more significant than the contribution of the ideal L2 self. Therefore, further research should focus on the relationship between these three components. This is explained in findings presented by (Dörnyei and Chan, 2013) in which they state that, although the ideal L2 self plays an important role in shaping the individual's motivational way of thinking, in many linguistic contexts, it lacks the power to make a difference in actual motivated behaviour. This is confirmed by findings which state that while respondents considered external pressure to be valid and intended to adjust their behaviour accordingly, this intended effort was not rewarded in their actual grades. This conclusion is confirmed by the findings of other researchers mentioned in the introductory part of this paper. They expressed considerable reluctance, stating that the ideal L2 cannot be used as a predictor of school grades, and thus, motivation for developing an ideal L2 through dominant visual aptitude is irrelevant to academic achievement. In addition, knowledge cannot be properly predicted by the ideal $L 2$, because no relation has been found between the ideal $L 2$ self and the actual performance in their idiodynamic paradigm, which measures individual motivational variability in certain time interval. The above-mentioned researchers did not find any evidence that the ideal L2 self is dynamic or that it adapts to the changing requirements of the task, and therefore, it does not provide any basis for predicting the actual behaviour (Al-Hoorie, 2018). Therefore, as previously mentioned, the L2MSS model requires further testing for the purpose of drawing safer conclusions about the significance of the ideal L2.

Finally, it should be noted that findings related with the significant relationship between the ideal L2 self and the willingness to communicate are insufficient for it to be considered a respectable predictor of success in maintaining motivation to learn a foreign language. This brings its motivational potential into question, which makes the second working hypothesis also open for discussion, i.e. it has not been fully confirmed, and the basic hypothesis can also be questioned, which confirms the doubts about the competence of the L2MSS structure.

\section{Regression}

The regression model with the willingness to communicate as a criterion was significant, $F(5$. $290)=4.34, p=0.001$, and the predictors explained about $7 \%(R 2=0.07$, adjusted $R 2=0.05)$ of the criterion variance. The relative influence of predictors is presented in Table 3 . The VIF indicator was close to 1 for all predictors, indicating that there were no problems with multicollinearity. L2 self was a significant positive predictor, indicating that higher grades are associated with a higher willingness to communicate. The period of time spent studying English/German language was a significant negative predictor, indicating that those who spent an average of several years learning English/German scored lower on the scale of willingness to communicate. These finding also agree with the previous ones, and support the general and first working hypothesis, confirming the significant predictor potential of the ideal L2 self, but deny the predictive significance of gender, the period of time spent studying $L 2$, and grades, i.e. the learning achievement. 
Šafranj, J., Gojkov-Rajić, A., \& Bogdanović, V. (2021). The ideal L2 self as a Factor of self-motivation in willingness to communicate, International Journal of Cognitive Research in Science, Engineering and Education (IJCRSEE), 9(2), 189-202.

Table 3.

Relative predictive power of predictors for willingness to communicate

\begin{tabular}{lccc}
\hline Predictor & Beta $(\beta)$ & $p$ & VIF \\
\hline Ideal L2 self & 0.23 & 0.000 & 1.23 \\
Gender & -0.03 & 0.504 & 1.06 \\
Country & 0.09 & 0.115 & 1.02 \\
Years of study & -0.15 & 0.010 & 1.05 \\
Grade & -0.02 & 0.721 & 1.23 \\
\hline
\end{tabular}

Important predictors for WTC are the L2 self and residing in the country where the target language is spoken (English/German). The L2 self is a positive predictor, meaning that those with a higher L2 self-score have higher willingness to communicate, which confirms the above statements about the hypotheses. When it comes to the period of time spent studying, the relation is reversed, which is a negative predictor. Willingness to communicate with those who have studied English/German for a longer period of time is generally lower (this relation is statistically significant, but of low intensity). This confirms the part of the third hypothesis, which assumes a significant positive relationship between the ideal L2 self and the time spent in the country where the target language is spoken, but not the part related to the variable period of time spent learning a foreign language. The part of this hypothesis that refers to the assessment of success in learning a foreign language was also confirmed in this study. It shows significance of this variable regarding willingness to communicate, but not the significance of the ideal L2 self.

\section{Moderations}

Only one of the four moderations tested was significant. The addition of the term interaction between the $L 2$ self and gender $(F(1,299)=3.52, p>0.05, L 2)$ and whether participants resided in the country where the target language is spoken $(F(1,299)=0.78, p>0.05)$ and the ideal $L 2$ self and level obtained $(F(1,299)=0.62, p>0.05)$ did not significantly improve the model.

The addition of the term interaction between $\mathrm{L} 2$ and the years spent studying a foreign language to moderation significantly improved the model $(F(1,292)=5.45, p=0.020)$. For the purpose of being understood better, this interaction is presented in Figure 2, where the results are shown in standardized units (z-score) at low (-1 SD), medium, and high (+1 SD) levels of $L 2$ and years spent studying a foreign language. At the low level of years spent studying a foreign language, willingness to communicate in those with high ideal L2 is higher compared to those with lower ideal L2 levels. This difference does not appear to be present at higher levels of years spent studying $L 2$ language, as willingness to communicate is similar, regardless of the level of the ideal L2 self.

Consequently, it could be concluded that the only significant interaction is the one between the ideal L2 self and the years spent studying L2 language, which means that the number of years spent studying a language moderates the relationship between the ideal L2 self and WTC. The interaction analyses whether the influence of the ideal L2 self on WTC varies at different moderator levels. The chart shows that the difference is higher at lower levels (fewer years spent studying English / German), and those with higher ideal L2 self also have a higher WTC, while the WTC of those who have studied English I German for a longer period of time is close to average, regardless of the level of ideal L2 self.

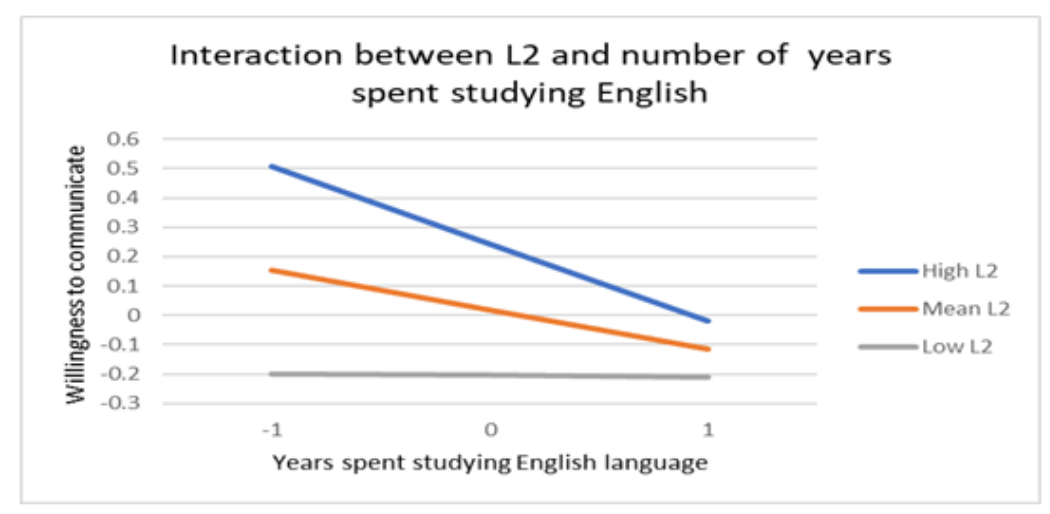

Figure 2. Interaction between ideal L2 self and years spent studying English/German language 
Šafranj, J., Gojkov-Rajić, A., \& Bogdanović, V. (2021). The ideal L2 self as a Factor of self-motivation in willingness to communicate, International Journal of Cognitive Research in Science, Engineering and Education (IJCRSEE), 9(2), 189-202.

The above conclusions further support the third hypothesis, because they confirm the significant influence of residing in the country where the target language is spoken, as well as that the duration of studying does not affect the interaction between the ideal $L 2$ self and the willingness to communicate, as the variable years spent studying failed to moderate this relationship in a positive direction. The assumption that interprets these findings has been stated above.

\section{Discussion}

The basic descriptive indicators for continuous variables suggest that the average values are normally distributed for the WTC and a high percentage of respondents $(68 \%)$ show high WTC selfassessment. The findings of the ideal L2 self, i.e. the L2 assessment is rather high. As for the position of the ideal L2 within the L2MSS motivational system, it could be concluded that these findings confirm the importance of the individuals' perception of their own potential, and that the perceived I/self can affect the realization of predicted behaviour, and in this case, that the respondents have a good motivational premise for directing their efforts towards gradually progressing from the current to a more desirable state. At this point, it is important to mention that the Heuristic L2 MSS Model (Dörnyei, 2006) confirmed its importance for further study of motivation in foreign language learning by affirming good position of the ideal L2 self. These findings are consistent with the findings of other researchers (Dörnyei and Ushioda, 2011; Papi and Teimouri, 2012) and confirm the logical paradigm of Dörnyei's L2 motivational self-system (Dörnyei, 2006, 2009a) which focuses on the student's L2-self perception, especially on the perception of the desired future self-efficacy. The findings also fit into the presented multidimensional construct given in Figure 1. (Heuristic model of L2 WTC, Macintyre et al., 1998), which includes psychological and communicative dimensions of language that are believed to be able to influence L2 WTC, such as personality traits, self-confidence, attitude, desires and willingness. Going one step further, here we can also include Bandura's (2001) social-cognitive theory in which beliefs regarding self-efficacy drive a person to perseverance, concentration, avoidance of confusion and further engagement in achieving the desired goals, i.e. success. Due to the complexity and range of psychological dimensions, self-confidence is considered a broader and more stable trait related to the individual's perception of his/her overall ability, and, therefore, important for learning foreign languages (Kleitman and Stankov, 2007).

Another significant conclusion relates to the fact that the ideal L2 self is strongly associated with residing in the country where the target language is spoken, as well as with the WTC (willingness to communicate in that specific language). This points to the possibility of including other aspects of motivation in addition to the ideal L2, which is significant for willingness to communicate in L2 language compared to other components of the observed model (indicating $L 2$ expectations projected and directed by others and L2 learning experience in the immediate learning environment, including aspects such as the teacher, the curriculum and the peers). Consequently, the status of the ideal L2 is not autonomous, which is indicated by correlations between L2 and student achievements (obtained grades in a foreign language). These findings are encountered in the research of Dörnyei and Chan (2013) who state that the ideal L2 has the status of the motivational driver, but other components of the L2MSS motivational system should also be taken into account for the overall achievement, and in this case, this construct can be significant for students' achievements, which does not destabilize the multidimensional construct of the L2 WTC Heuristic Model, but rather complements its structure. Further research would be required to confirm this statement, because other research findings (Martinović, 2018; Maclntire and Doucette, 2010) suggest that, even though self plays an important role in shaping the individual's motivational mindset, in many linguistic contexts, it lacks the power to make a difference in actual motivated behaviour. It is also noteworthy to identify external pressure (grades, tests ...) as an important factor for adjusting students' behaviour accordingly. The findings of other researchers (Al-Hoorie, 2018; Dörnyei, 2014) also display certain retention, stating that the ideal L2 self cannot be used as a reliable predictor of school grades. Therefore, they conclude that motivation to develop an ideal L2 through dominant visual propensity is insufficient for certain level of academic achievement and that the ideal L2 self cannot predict knowledge with certainty. This is because connection has been found between the ideal L2 self and the actual performance in their idiodynamic paradigm, which measures individual motivational variability in a determined time interval (Dörnyei, 2009b). It must be pointed out that these researchers lack evidence that the ideal L2 is self- dynamic, or that it adapts to the changing requirements of the task. They conclude that insufficient basis for safe prediction of actual behaviour has been provided, i.e. that the motivational matrix includes other L2 concepts (it should be L2 self and experiential L2 self) (Al-Hoorie, 2018; Williams, Mercer and Ryan, 2016; Markus and Nurius, 1986). This suggests the need for further analyses of the 
Šafranj, J., Gojkov-Rajić, A., \& Bogdanović, V. (2021). The ideal L2 self as a Factor of self-motivation in willingness to communicate, International Journal of Cognitive Research in Science, Engineering and Education (IJCRSEE), 9(2), 189-202.

ideal L2 self, and, consequently, the observed L2MSS model. Further studies on this model should be focused more on the other two components. As some other researchers point out (Martinović, 2018; Maclntire and Doucette, 2010), special emphasis should be put on $L 2$ learning experience because it is directly related to the motivational context in the classroom (i.e. the teaching, the curriculum) where $\mathrm{L} 2$ learning and teaching take place.

Negative correlation between the duration of language learning and the willingness to communicate is an issue that may be explained if we analyse the way in which foreign languages are taught in Serbia. Foreign languages are learned from an early preschool age; however, there are numerous challenges that must be taken into consideration. Children are taught by graduates in private schools of foreign languages. Due to the fact that there is a lack of personnel with a degree, the curriculum is poorly structured and the lessons take place only twice a week for half an hour. Notwithstanding these challenges, there are possible solutions that can help overcome the above-mentioned difficulties - foreign language learning modules providing foreign language learning for educators at faculties specialising in teacher education, as well as language learning during free activities in preschool institutions (Prtljaga, 2021).

\section{Conclusion}

This study has been dedicated to analysing the power that the ideal L2 self has to contribute to students' actual motivated behaviour in situations of foreign language communication. It aims at investigating the predictive validity of the ideal L2 self, when it comes to willingness to communicate in a given foreign language, as well as the importance of the construction of motivation models. This could propose a clearer orientation in directing motivation in foreign language communication. The surveyed students have shown good motivational assumption for directing their efforts to progress gradually from the current to a more desirable state, because their willingness to reach the visualised standards of the personal ideal self is high, i.e. their ideal L2 within the L2MSS is high. Based on everything stated above, it can be concluded that this self-awareness towards the acquisition of new skills and strategies in the field of foreign languages could be expected to turn into motivation and become an incentive to invest more effort in developing the intended behaviour. However, findings related with the importance of success regarding grades in foreign language proficiency in terms of willingness to communicate suggest the need to reconsider the predictive value of the ideal L2 self.

Suggestions for further research are as follows: the findings indicate that the ideal L2 self should be divided into two constructs: obligations that one would like to comply with and obligations that others expect to be complied with. Contribution of the ideal L2 experience should also be considered for the purpose of assessing the contribution of these components in terms of improving the original construction by quantifying the predictive validity of components of which the L2 MSS construct consists. Otherwise, it is difficult to determine the progress of the model's design and what to do with it in practice.

\section{Acknowledgements}

The authors would like to express their gratitude to all the participants of the research and to all the colleagues for their support in writing this paper.

\section{Conflict of interests}

The authors declare no conflict of interest.

\section{References}

Al-Hoorie, A. H. (2018). The L2 motivational self system: A meta-analysis. Studies in Second Language Learning and Teaching, 8(4), 721-754. https://doi.org/10.14746/ssllt.2018.8.4.2

Baker, S. C., \& MacIntyre, P. D. (2003). The role of gender and immersion in communication and second language orientations. Language learning, 53(S1), 65-96. https://doi.org/10.1111/0023-8333.00224

Bandura, A. (2001). Social cognitive theory: An agentic perspective. Annual review of psychology,52(1), 1-26.https://doi. org/10.1146/annurev.psych.52.1.1

Boo, Z., Dörnyei, Z., \& Ryan, S. (2015). L2 motivation research 2005-2014: Understanding a publication surge and a changing landscape. System, 55, 145-157. https://doi.org/10.1016/j.system.2015.10.006

Donovan, L. A., \& Maclntyre, P. D. (2004). Age and sex differences in willingness to communicate, communication apprehension, and self-perceived competence. Communication Research Reports, 21(4), 420-427. https://doi. org/10.1080/08824090409360006 
Šafranj, J., Gojkov-Rajić, A., \& Bogdanović, V. (2021). The ideal L2 self as a Factor of self-motivation in willingness to communicate, International Journal of Cognitive Research in Science, Engineering and Education (IJCRSEE), 9(2), 189-202.

Dörnyei, Z. (2006). The psychology of the language learner: Individual differences in second language acquisition. TESLEJ, 10(1). Retrieved from http://www.cc.kyoto-su.ac.jp/information/tesl-ej/ej37/r7.html

Dörnyei, Z. (2009a). The L2 motivational self system. In Z. Dörnyei\& E. Ushioda (Eds.), Motivation, language identity and the L2 self (pp. 9-42). Bristol, UK: Multilingual Matters.https://doi.org/10.21832/9781847691293-003

Dörnyei, Z. (2009b). Motivation, language identities and the L2 Self: Future research directions. In: Z. Dörnyei\& E. Ushioda (Eds.), Motivation, language identity and the L2 self (pp. 350-356). Multilingual Matters.https://doi. org/10.21832/9781847691293-019

Dörnyei, Z. (2014). Motivation in second language learning: In M. Celce-Murcia, DM Brinton \& MA Snow (eds.). Teaching English as a second or foreign language: 518-531. Boston. National Geographic Learning/Cengage Learning.

Dörnyei, Z., \& Chan, L. (2013). Motivation and vision: An analysis of future L2 self images, sensory styles, and imagery capacity across two target languages. Language Learning, 63(3), 437-462. https://doi.org/10.1111/lang.12005

Dornyei, Z., \& Ryan, S. (2015). The Psychology of the Language Learner Revisited (1 ${ }^{\text {st }}$ ed.). Routledge. https://doi. org/10.4324/9781315779553

Dörnyei, Z., \& Taguchi, T. (2009).Questionnaires in second language research: Construction, administration, and processing. Routledge. https://doi.org/10.4324/9780203864739

Dörnyei, Z., \&Ushioda, E. (2011). Teaching and researching motivation (2nd ed.). Harlow, UK: Longman.

Evtyugina, A., Zhuminova, A., Grishina, E., Kondyurina, I., \& Sturikova, M. (2020). Cognitive-Conceptual Model for Developing Foreign Language Communicative Competence in Non-Linguistic University Students. International Journal of Cognitive Research in Science, Engineering and Education (IJCRSEE), 8(Special issue), 69-77. https://doi.org/10.23947/23348496-2020-8-SI-69-77

Gardner, G., Gardner, A., Middleton, S., Della, P., Kain, V., \& Doubrovsky, A. (2010). The work of nurse practitioners. Journal of Advanced Nursing, 66(10), 2160-2169. https://doi.org/10.1111/j.1365-2648.2010.05379.x

Ghanizadeh, A., Eishabadi, N., \& Rostami, S. (2016). Motivational dimension of willingness to communicate in L2: The impacts of criterion measure, ideal L2 self, family influence, and attitudes to L2 culture. International Journal of Research Studies in Education, 5(3), 13-24. https://doi.org/10.5861/ijrse.2015.1261

Ghanizadeh, A., \& Rostami, S. (2015). A Dörnyei-inspired study on second language motivation: A cross-comparison analysis in public and private contexts. Psychological Studies, 60(3), 292-301. https://doi.org/10.1007/s12646-015-0328-4

Gojkov-Rajić, A., Stojanović, A., Šafranj,J. \& Gojkov,G. (2021a). Didaktički aspekti samoregulacije učenja darovitih, [Didactic aspects of self-regulation of gifted learning], Monograph, Srpska akademija obrazovanja, Beograd, p.260.

Gojkov-Rajić, A., Šafranj, J.\& Gojkov,G. (2021b). Relationship between didactic instructions and metacognition in foreign language learning. In: Herzog, J. (Ed.) Giftedness in a Variety of Educational Fields (57-79). Verlag Dr.Kovač GmbH, Hamburg.

Hayes, A. F. (2009). Beyond Baron and Kenny: Statistical Mediation Analysis in the New Millennium, Communication Monographs, 76(4), 408-420, https://doi.org/10.1080/03637750903310360

Henry, A., Davydenko, S., \& Dörnyei, Z. (2015). The anatomy of directed motivational currents: Exploring intense and enduring periods of L2 motivation. The Modern Language Journal, 99(2), 329-345. https://doi.org/10.1111/modl.12214

Higgins, E.T. (1987). Self-discrepancy: A theory relating self and affect. Psychological Review, 94(3), 319-340. https://doi. org/10.1037/0033-295X.94.3.319

Islam, M., Lamb, M., \& Chambers, G. (2013). The L2 motivational self system and national interest: A Pakistani perspective. System, 41, 231-244. https://doi.org/10.1016/j.system.2013.01.025

Kanat-Mutluoğlu, A. (2016). The influence of ideal L2 self, academic self-concept and intercultural communicative competence on willingness to communicate in a foreign language. Eurasian Journal of Applied Linguistics, 2(2), 27-46. https://doi. org/10.32601/ejal.461012

Kim, S. J. (2004).Exploring willingness to communicate (WTC) in English among Korean EFL (English as a foreign language) students in Korea: WTC as a predictor of success in second language acquisition. (Unpublished Doctoral Dissertation). The Ohio State University. Retrieved from https://etd.ohiolink.edu/apexprod/rws_etd/send_file/send?accession=osu1 101267838\&disposition=inline

Kim, Y. K., \& Kim, T. Y. (2011). The effect of Korean secondary school students' perceptual learning styles and ideal L2 self on motivated L2 behavior and English proficiency. Korean Journal of English Language and Linguistics,11(1), 21-42.

Kleitman, S., \& Stankov, L. (2007). Self-confidence and metacognitive processes. Learning and Individual Differences, 17(2), 161-173. https://doi.org/10.1016/j.lindif.2007.03.004

Lamb, M. (2012). A self system perspective on young adolescents' motivation to learn English in urban and rural settings. Language Learning, 62(4), 997-1023. https://doi.org/10.1111/j.1467-9922.2012.00719.x

MacIntyre, P. D., Clément, R., Dörnyei, Z., \& Noels, K. A. (1998). Conceptualizing willingness to communicate in a L2: A situational model of L2 confidence and affiliation. The Modern Language Journal, 82(4), 545-562. https://doi. org/10.1111/j.1540-4781.1998.tb05543.x

Macintyre, P. D., \& Doucette, J. (2010). Willingness to communicate and action control. System, 38(2), 161-171.https://doi. org/10.1016/j.system.2009.12.013

Maclntyre, P.D. \& A. Serroul, (2015). Motivation on a Per-Second Timescale: Examining Approach-Avoidance Motivation During L2 Task Performance. In Z. Dörnyei, P.D. Maclntyre\& A. Henry (Eds.), Motivational Dynamics in Language Learning (pp. 109-138), Bristol, UK: Multilingual Matters. https://doi.org/10.21832/9781783092574-013

Marks, M., Fairris, D., \& Beleche, T. (2012). Do course evaluations truly reflect student learning. Economics of Education Review, 31(5), 709-719. https://doi.org/10.1016/j.econedurev.2012.05.001

Markus, H. R., \& Nurius, P. (1986). Possible selves. American Psychologist, 41(9), 954-969. https://doi.org/10.1037/0003066X.41.9.954

Martinović, A. (2018). The L2 motivational self system: Differences among learners, Jezikoslovlje,19(1), 133-157, University of Zadar, Zadar.

McCroskey, J. C. (1992). Reliability and validity of the willingness to communicate scale. Communication Quarterly,40(1), 1625. https://doi.org/10.1080/01463379209369817

Mehmet, S. A. K. (2020). The role of ideal L2 self in predicting L2 willingness to communicate inside and outside the classroom.

www.ijcrsee.com 
Šafranj, J., Gojkov-Rajić, A., \& Bogdanović, V. (2021). The ideal L2 self as a Factor of self-motivation in willingness to communicate, International Journal of Cognitive Research in Science, Engineering and Education (IJCRSEE), 9(2), 189-202.

Eurasian Journal of Applied Linguistics, 6(2), 189-203. https://doi.org/10.32601/ejal.775798

Moskovsky, C., Assulaimani, T., Racheva, S., \& Harkins, J. (2016). The L2 motivational self system and L2 achievement: A study of Saudi EFL learners. The Modern Language Journal, 100(3), 641-654. https://doi.org/10.1111/modl.12340

Munezane, Y. (2013). Attitudes, affect and ideal L2 self as predictors of willingness to communicate. Eurosla Yearbook, 13(1), 176-198. https://doi.org/10.1075/eurosla.13.09mun

Munezane, Y. (2015). Enhancing willingness to communicate: Relative effects of visualization and goal setting. The Modern Language Journal, 99(1), 175-191. https://doi.org/10.1111/modl.12193

Noels, K. A. (2009). The Internalisation of Language Learning into the Self and Social Identity. In Motivation, language identity and the L2 self (pp. 295-313). Multilingual Matters. https://doi.org/10.21832/9781847691293-016

Öz, H. (2016). Role of the ideal L2 self in predicting willingness to communicate of EFL students. In İ. H. Mirici, İ. H. Erten, H. Öz, \& I. Vodopija-Krstanovic (Eds.), Research papers as an Additional Language (pp. 163-182). Rijeka: Faculty of Humanities and Social Research.

Papi, M. \&Abdollahzadeh, E. (2012). Teacher Motivational Practice, Student Motivation, and Possible L2 Selves: An Examination in the Iranian EFL Context. Language Learning, 62(2), 571-594. https://doi.org/10.1111/j.1467-9922.2011.00632.x

Papi, M., \& Teimouri, Y. (2012). Dynamics of selves and motivation: a cross-sectional study in the EFL context of Iran. International Journal of Applied Linguistics, 22(3), 287-309. https://doi.org/10.1111/j.1473-4192.2012.00312.x

Peng, J. E. (2007). Willingness to communicate in an L2 and integrative motivation among college students in an intensive English language program in China. University of Sydney papers in TESOL, 2(1), 33-59. https://citeseerx.ist.psu.edu/ viewdoc/download?doi=10.1.1.561.3662\&rep=rep1\&type=pdf

Peng, J. E. (2012). Towards an ecological understanding of willingness to communicate in EFL classrooms in China. System, 40(2), 203-213. https://doi.org/10.1016/j.system.2012.02.002

Peng, J. E. (2015). L2 motivational self system, attitudes, and affect as predictors of L2 WTC: An imagined community perspective. The Asia-Pacific Education Researcher, 24(2), 433-443. https://doi.org/10.1007/s40299-014-0195-0

Peng, J. E., \& Woodrow, L. (2010). Willingness to communicate in English: A model in the Chinese EFL classroom context. Language learning, 60(4), 834-876.https://doi.org/10.1111/j.1467-9922.2010.00576.x

Prtljaga, J. (2021).Učenje i poučavanje engleskog jezika na ranom uzrastu [Learning and teaching English at an early age], Vršac, VŠSS, "M. Palov".

Shirvan, M. E., Khajavy, G. H., MacIntyre, P. D., \&Taherian, T. (2019). A meta-analysis of L2 willingness to communicate and its three high-evidence correlates. Journal of psycholinguistic research, 48(6), 1241-1267. https://doi.org/10.1007/ s10936-019-09656-9

Tabachnick, B. G., \& Fidell, L. S. (2013). Using Multivariate Statistics, $6^{\text {th }}$ Edition, California State University of Northridge.

Teimouri, Y. (2017). L2 selves, emotions, and motivated behaviors. Studies in Second Language Acquisition, 39(4), 681-709. https://doi.org/10.1017/S0272263116000243

Ushioda, E. (2011). Language learning motivation, self and identity: Current theoretical perspectives, Computer Assisted Language Learning, 24(3), 199-210.https://doi.org/10.1080/09588221.2010.538701

Williams, M., Mercer, S., \& Ryan, S. (2016). Exploring psychology in language learning and teaching. Oxford University Press.

Yashima, T. (2002). Willingness to communicate in a second language: The Japanese EFL context. The Modern Language Journal, 86(1), 54-66. https://doi.org/10.1111/1540-4781.00136

Yashima, T., Zenuk-Nishide, L., \& Shimizu, K. (2004). The influence of attitudes and affect on willingness to communicate and second language communication. Language Learning, 54(1), 119-152. https://doi.org/10.1111/j.14679922.2004.00250.x

Yu, M. (2008). Willingness to communicate of foreign language learners in a Chinese setting. (Unpublished doctoral dissertation). Florida State University, Tallahassee.

You, C., Dörnyei, Z., \& Csizér, K. (2016). Motivation, vision, and gender: A survey of learners of English in China. Language Learning, 66(1), 94-123. https://doi.org/10.1111/lang.12140

Zarrinabadi, N. (2014). Communicating in a second language: Investigating the effect of teacher on learners' willingness to communicate. System, 42, 288-295. https://doi.org/10.1016/j.system.2013.12.014 